\title{
An approximate theory of the ozone isotopic effects: Rate constant ratios and pressure dependence
}

\author{
Yi Qin $\mathrm{Gao}^{\mathrm{a})}$ \\ Department of Chemistry, Texas A\&M University, College Station, Texas 77843, USA \\ R. A. Marcus ${ }^{\text {b) }}$ \\ Noyes Laboratories, 127-72, California Institute of Technology, Pasadena, California 91125, USA
}

(Received 12 July 2007; accepted 15 October 2007; published online 28 December 2007)

\begin{abstract}
The isotopic effects in ozone recombination reactions at low pressures are studied using an approximate theory which yields simple analytic expressions for the individual rate constant ratios, observed under "unscrambled" conditions. It is shown that the rate constant ratio between the two competing channels $\mathrm{XYZ} \rightarrow \mathrm{X}+\mathrm{YZ}$ and $\mathrm{XYZ} \rightarrow \mathrm{XY}+\mathrm{Z}$ is mainly determined by the difference of the zero-point energies of diatomic molecules $\mathrm{YZ}$ and $\mathrm{XY}$ and by the efficiency of the deactivation of the newly formed excited ozone molecules, whereas the mass-independent fractionation depends on a "nonstatistical" symmetry factor $\eta$ and the collisional deactivation efficiency. Formulas for the pressure effects on the enrichment and on the rate constant ratios are obtained, and the calculated results are compared with experiments and more exact calculations. In all cases, ratios of isotope rates and the pressure dependence of enrichments, the agreement is good. While the initial focus was on isotope effects in the formation of $\mathrm{O}_{3}$, predictions are made for isotope effects on ratios of rate constants in other reactions such as $\mathrm{O}+\mathrm{CO} \rightarrow \mathrm{CO}_{2}, \mathrm{O}+\mathrm{NO} \rightarrow \mathrm{NO}_{2}$, and $\mathrm{O}+\mathrm{SO} \rightarrow \mathrm{SO}_{2}$.

(C) 2007 American Institute of Physics. [DOI: 10.1063/1.2806189]
\end{abstract}

\section{INTRODUCTION}

Unusual and unexpected isotopic effects in ozone formation have been the subject of many experimental and theoretical studies. ${ }^{1-36}$ There exist mainly two types of experimental observations: an unusual "mass-independent" isotopic fractionation (MIF) of ozone ${ }^{1-23}$ and a large unconventional highly "mass-dependent" isotope effect observed in the various rate constant ratios. ${ }^{25-29}$ Rice-RamspergerKassel-Marcus (RRKM) theory with a master equation approach for the collisional deactivation of the intermediate excited ozone molecules has been applied to study both phenomena. ${ }^{32-34}$ It was found that the MIF can be explained when an $\eta$-effect, a non-RRKM effect, ${ }^{30-34}$ which reduces dynamically the low-pressure rate constant of the recombination to form symmetric molecules by a factor of $\eta$ compared to that for the asymmetric ones, and a weak collision effect $^{32-34}$ for the deactivation of excited ozone molecules is also included in the theory. For the unusually large massdependent isotope effect, observed under very special ("unscrambled") experimental conditions, the zero-point energy differences in the two dissociation paths of any asymmetric $\mathrm{XYZ}^{*}$ isotopomer play the key role, together with the weak collision efficiency. ${ }^{32-34}$ Earlier the large mass-dependent effect for unscrambled systems had been empirically correlated with many properties, all functionally related, ${ }^{32}$ including zero-point energy differences ${ }^{32,37}$ of the two dissociation channels of an asymmetric $X Y Z^{*}$. The proof that of these properties it was the zero-point differences that was responsible was given in Refs. 32 and 33.

\footnotetext{
${ }^{a)}$ Electronic mail: yiqin@mail.chem.tamu.edu.

b)Electronic mail: ram@caltech.edu.
}

The mass-dependent and mass-independent effects found in experiments are evident in these unscrambled and "scrambled" systems, respectively. The former contains only $\mathrm{XX}$ and $\mathrm{YY}$ isotopomers of $\mathrm{O}_{2}$, while in scrambled systems the heteronuclear XY also exists as a reactant. Accordingly, in unscrambled experiments vibrationally excited ozone isotopomers XYY are formed only from $\mathrm{X}+\mathrm{YY} \rightarrow \mathrm{XYY}$, while in scrambled experiments they are also formed from $Y$ $+\mathrm{XY} \rightarrow \mathrm{XYY}$. The relative importance of the two dissociation channels of XYY in the theory is determined by a "partitioning factor," 30 which in turn depends on whether the access to the dissociating $X Y Y^{*}$ was from one or both channels $(\mathrm{X}+\mathrm{YY}$ and $\mathrm{Y}+\mathrm{XY})$. This difference in experimental conditions leads to a marked difference in the theoretical expressions for the two types of experiments.

RRKM theory is again used in the present study as the zeroth-order theory with a small correction for the lowpressure rate constant for symmetric isotopomeric ozone molecules, XXX and XYX, as compared with the asymmetric ones YXX or YXZ is made. This correction is apart from the usual symmetry numbers, which are also included. An origin of this $\eta$-effect was discussed elsewhere. ${ }^{32,33}$ To calculate rate constant ratios between different reactions, an approximate formalism is given in the present study. The pressure dependence of rate constant ratios and enrichments is also considered.

In applying the RRKM formalism, the number of states at the transition state is assumed to be a simple function of the excess energy, an assumption based on earlier calculations. The calculated results for the rate constant ratios and enrichments are compared with experimental results and also with our previous more detailed calculations. The paper is 
organized as follows. Expressions for low-pressure rate constant ratios are obtained in Sec. II, and those for pressure effects on enrichment and rate constant ratios are obtained in Sec. III. The results are discussed in Sec. IV.

\section{LOW-PRESSURE RECOMBINATION RATE CONSTANTS}

\section{A. General remarks}

The chemical kinetics scheme for the formation of ozone can be written as follows:

$$
\begin{aligned}
& \mathrm{X}+\mathrm{YZ} \rightarrow \mathrm{XYZ}(E J), \quad k_{r}^{a}(E J) \\
& \mathrm{XYZ}(E J)+\mathrm{M} \rightarrow \mathrm{XYZ}\left(E^{\prime} j^{\prime}\right)+\mathrm{M}, \quad \omega\left(E J \rightarrow E^{\prime} J^{\prime}\right), \\
& \mathrm{XYZ}\left(E^{\prime} J^{\prime}\right) \rightarrow \mathrm{X}+\mathrm{YZ}, \quad k_{d}^{a}\left(E^{\prime} J^{\prime}\right) \\
& \mathrm{XYZ}\left(E^{\prime} J^{\prime}\right) \rightarrow \mathrm{XY}+\mathrm{Z}, \quad k_{d}^{b}\left(E^{\prime} J^{\prime}\right)
\end{aligned}
$$

and, in a series of steps, a stable ozone molecule of energy $E^{\prime}$ is formed,

$$
\mathrm{XYZ}(E J)+\mathrm{M} \rightarrow \mathrm{XYZ}\left(E^{\prime} J^{\prime}\right)+\mathrm{M}, \quad \omega\left(E J \rightarrow E^{\prime} J^{\prime}\right)
$$

where $E^{\prime}$ is an energy sufficiently below the dissociation threshold that the XYZ has a negligible chance of reacquiring enough energy to dissociate. Only $E$ and the total angular momentum $J$ are conserved in individual reaction steps Eqs. (1), (3), and (4). The $k_{r}^{a}(E J), k_{d}^{a}\left(E^{\prime} J^{\prime}\right)$, and $k_{d}^{b}\left(E^{\prime} J^{\prime}\right)$ are $E$ and $J$-dependent rate constants of the recombination and dissociation reactions, respectively, and $\omega\left(E J \rightarrow E^{\prime} J^{\prime}\right)$ is the rate per unit $E$ of forming $\mathrm{XYZ}$ at $\left(E^{\prime} J^{\prime}\right)$ from $(E J)$ by a collision with a third body M. For the dissociation of XYZ, there exist the two distinguishable exit channels $a$ and $b$ when $\mathrm{X} \neq \mathrm{Z}$ [Eqs. (3) and (4)]. For a symmetric molecule, where $X=Z$, the designation $(a, b)$ is omitted. By convention, channel $a$ is the one with the lower zero-point energy of the diatomic species. Thus, the YZ in Eq. (3) has a lower zero-point energy than the XY in Eq. (4). As seen later, the difference in the zero-point energies of the two channels plays an essential role in determining the rate constant ratios.

The main assumptions used in the present study are (1) the conventional isotopic effects are small compared to unconventional ones and thus can be neglected (see Appendix A). (2) An exponential-down model is assumed for the energy transfer [Eqs. (6)-(9)] together with a weak collision approximation for the stabilization of the excited ozone molecules [Eqs. (10)-(12)]. (3) Based on earlier calculations, ${ }^{33}$ the number of states of the transition state is assumed to be linearly dependent on the excess energy of the ozone (the energy of the system minus the energy at the lower dissociation threshold $E_{b}$ ). (4) An effective density of states of the ozone molecule $\Sigma_{J} \rho(E J) Y_{a}(E J)$, where $Y_{a}$ is a partitioning factor, ${ }^{30}$ used in Eq. (16) is assumed to be linearly dependent on the excess energy, also based on the detailed calculations in Ref. 33. More details of each assumption are given during the course of the derivation.

\section{B. Derivation}

For the collisional deactivation of the excited ozone molecules, ${ }^{38}$ an exponential-down energy transfer model ${ }^{39}$ with a strong collisional angular momentum transfer assumption is used in the present study. In the exponential-down model, the probabilities for energy transfer are written as ${ }^{39}$

$$
\begin{aligned}
& q_{i j}=C e^{-\left|E_{i}-E_{i}\right| / \gamma^{\prime}}, \quad E_{j}<E_{i}, \\
& q_{i j}=C e^{-\left|E_{l}-E_{l}\right| / \gamma}, \quad E_{j}>E_{i},
\end{aligned}
$$

where

$$
C=\frac{1+\gamma / k_{B} T}{\gamma\left(2+\gamma / k_{B} T\right)} .
$$

In the above equations $\gamma$ is the averaged loss of energy per deactivational collision, $\gamma^{\prime}$ is the averaged gain of energy per activational collision, and

$$
\gamma^{\prime}=\gamma k_{B} T /\left(\gamma+k_{B} T\right) \text {. }
$$

In earlier studies, ${ }^{32-34,37}$ the lowest value of $E^{\prime}$ was chosen by lowering $E^{\prime}$ until the rate constant calculation converged. In the present study, the zero of $E^{\prime}$ is taken as the dissociation threshold of channel $a$. It has been shown ${ }^{33}$ that under the low-pressure limit, the choice of $E^{\prime}$ at the bottom of the potential well of ozone gives a common factor for the formation rate constants of all isotopomers, compared with the results obtained by setting it at the dissociation threshold. In the present study we are only interested in rate constant ratios and so the simplification of treating ozone states below the dissociation threshold of channel $a$ as a sink has only a minor influence on the results.

Under the assumptions given above and using a steadystate approximation, the low-pressure rate constant for the formation of an asymmetric molecule XYZ channel can be expressed as

$$
k_{b i}^{0, b}=\omega \int_{\varepsilon=0}^{\infty} p(E) \sum_{J} \frac{k_{r}^{b}(E J)}{k_{d}^{a}(E J)+k_{d}^{b}(E J)} d E,
$$

where $\omega$ is the total collisional frequency,

$$
\omega=\int_{\varepsilon^{\prime}} \sum_{j^{\prime}} \omega\left(E J \rightarrow E^{\prime} J^{\prime}\right) d E^{\prime} .
$$

For the convenience of discussion, the zero of energy is set at the asymptotic of the potential energy surface for the dissociation of ozone through channel $a$ (the channel with the smaller zero-point energy) to an oxygen atom and an oxygen molecule.

A rigorous treatment of the stabilization of the excited ozone molecule through collisions can be obtained by solving master equations involving reactions and collisional energy transfer and factorization schemes exist for the reduction of a two-dimensional master equation to a onedimensional one which satisfy a microscopic detail balance. ${ }^{40}$ For simplicity, in this paper, an approximate relation which takes into account the fact that newly formed ozone with higher energies is less likely to be deactivated to form a stable ozone will be used. In this approximation, the 
$J$ dependence of the deactivation is treated to be implicit and only the dependence on energy is expressed explicitly. The $p(E)$ in Eq. (10) is approximated to be proportional (with a factor of $\alpha$, which describes the probability that a deactivated ozone, by one collision, eventually becomes a stable ozone molecule) to the probability of the transition of an excited ozone molecule with energy of $E$ to a state below the dissociation threshold via a single collision with the bath molecule. It is then obtained by an integration of Eq. (6),

$$
p(E)=\alpha \int_{\Delta E=E-E_{a}}^{\infty} C e^{-\Delta E / \gamma} d \Delta E=\alpha C \gamma e^{-\left(E-E_{a}\right) / \gamma},
$$

where $E_{a}$ is the zero-point energy of the oxygen fragment in channel $a$. Using RRKM theory, the rate constants in Eq. (10) can be written as

$$
\begin{aligned}
& k_{r}^{b}(E J)=\frac{N_{b}(E J)}{h Q_{b}} e^{-E / k_{B} T}, \quad k_{d}^{b}(E J)=\frac{N_{b}(E J)}{h \rho(E J)}, \\
& k_{d}^{a}(E J)=\frac{N_{a}(E J)}{h \rho(E J)},
\end{aligned}
$$

where $N_{b}(E J)$ is the number of states at the transition state for channel $b, h$ is Planck's constant, $Q_{b}$ is the partition function of reactants of channel $b$, and $\rho(E J)$ is the density of states of the ozone molecule XYZ. Similar expressions are used for channel $a$. Substitution of Eqs. (12) and (13) into Eq. (10) yields

$$
k_{b i}^{0, b}=\frac{\omega \alpha C}{Q_{b}} \int_{E=E_{a}}^{a}\left[\sum_{j} \rho(E J) Y_{h}(E J)\right] e^{-\beta E} e^{-\left(E-E_{a}\right) / \gamma} d E,
$$

where $E_{a}$ is the zero-point energy of the oxygen fragment in channel $a$, and $\mathrm{Y}_{a, b}$, the partitioning factor ${ }^{30}$ is

$$
Y_{a, b}(E J)=\frac{N_{a, b}(E J)}{N_{a}(E J)+N_{b}(E J)} .
$$

A similar expression can be obtained for the recombination via channel $a$,

$$
k_{b i}^{0, a}=\frac{\omega \alpha C}{Q_{a}} \int_{E=E_{a}}^{\infty}\left[\sum_{J} \rho(E J) Y_{a}(E J)\right] e^{-\beta E} e^{-\left(E-E_{a}\right) / \gamma} d E .
$$

\section{Ratio of rate constants of $X+Y Z \rightarrow X Y Z$ and $X Y+Z$ $\rightarrow \mathrm{XYZ}$}

The rate constant ratios between the two channels of the formation of XYZ are independent of the $\eta$-effect because the intermediate $\mathrm{XYZ}^{*}$ has the same symmetry, regardless of the exit channel. They are considered in this section.

To use Eq. (14), approximations for the term $\Sigma_{J} \rho(E J) Y_{a}(E J)$ based on earlier calculations are made. First, we approximate $\Sigma_{J} \rho(E J) N_{b}(E J) /\left(N_{a}(E J)+N_{b}(E J)\right)$ by $\left[\Sigma_{J} \rho(E J) h\left(N_{b}(E J)\right)\right] N_{b}(E) /\left(N_{a}(E)+N_{b}(E)\right)$, where $h(N)$ is a unit step function and $N_{a}(E)=\Sigma_{J} N_{a}(E J), N_{b}(E)=\Sigma_{J} N_{b}(E J)$. It has been shown in Fig. 11 of Ref. 33 that an approximation

$$
\sum_{J} \rho(E J) h\left(N_{b}(E J)\right)=C_{\rho}^{b}\left(E-E_{b}\right)
$$

is appropriate, where $E-E_{b}$ is the excess energy and $E_{b}$ is the zero-point energy of the oxygen fragment involved in channel $b$. The $C_{\rho}^{b}$ in Eq. (17) is a constant determined mainly by the moment of inertia of the hindered rotor in channel $b$. An approximate relation between the $C_{\rho}^{b}$, s for different ozone molecules is given in Appendix A.

If $N_{a, b}(E)$ is assumed to depend on the excess energy in the form of $C_{a, b}\left(E-E_{a, b}\right)^{x}$, where $C_{a, b}$ and $x$ are constants, $x$ approximately equals 1 when a hindered-rotor transition state is used (Fig. 3 of Ref. 33). In this way we can write the number of states for channel $b$ as $N_{b}(E)=C_{b}\left(E-E_{b}\right)^{x} h(E$ $-E_{b}$ ), where $C_{b}$ is a constant, the number of states for channel $a$ as $N_{a}(E)=C_{a}\left(E-E_{b}+\Delta E_{0}\right)^{x} h\left(E-E_{b}+\Delta E_{0}\right)$, where $\Delta E_{0}=E_{b}-E_{a}$ is the zero-point energy difference between the two channels. In the present simplified treatment, in which the traditional kinetic isotopic effects are neglected, $C_{a}$ and $C_{b}$ will be approximated as being equal in estimating partitioning factors. Using these approximations the low-pressure rate constant for the recombination via channel $b$ can be written as

$$
k_{b i}^{0, h}=\frac{\omega \alpha C C_{\rho}^{b}}{Q_{b}} e^{-\beta E_{b}} e^{-\Delta E_{0} / \gamma} \int_{E=0}^{\infty} \frac{E^{2}}{2 E+\Delta E_{0}} e^{-\beta^{\prime} E} d E,
$$

where $\beta^{\prime}=\beta+1 / \gamma$. Integration of the right-hand side of Eq. (18) yields

$$
\begin{aligned}
k_{b i}^{0, h}= & \frac{\omega \alpha C C_{\rho}^{b}}{2 Q_{b} \beta^{\prime 2}} e^{-\beta E_{b}} e^{-\Delta E_{0} / r}\left(1-\frac{\Delta E_{0} \beta^{\prime}}{2}\right. \\
& \left.+\left(\frac{\Delta E_{0} \beta^{\prime}}{2}\right)^{2} e^{\Delta E_{0} \beta^{\prime} / 2} \Gamma\left(0, \frac{\Delta E_{0} \beta^{\prime}}{2}\right)\right),
\end{aligned}
$$

where $\Gamma\left(0, \Delta E_{0} \beta^{\prime} / 2\right)$ is an incomplete gamma function.

When $\Delta E_{0} \beta^{\prime} / 2$ is small, as is typically the case, $k_{b i}^{0, b}$ can be further approximated as

$$
k_{b i}^{0, h}=\frac{\omega \alpha C C_{\rho}^{b}}{2 Q_{b} \beta^{\prime 2}} e^{-\beta E_{b}} e^{-\left(\beta^{\prime} / 2+1 / \gamma\right) \Delta E_{0}} .
$$

To obtain an expression for the rate constant of recombination via channel $a$, we make use of Eqs. (14) and (15), and Eq. (16) can be written as

$$
\begin{aligned}
k_{b i}^{0, a}= & \frac{\omega \alpha C}{Q_{a}} \int_{E=E_{a}}^{\infty} \sum_{J} \rho(E J)\left[h\left(N_{a}(E J)+N_{b}(E J)\right)\right. \\
& \left.-Y_{b}\right] e^{-\beta E} e^{-\left(E-E_{a}\right) / \gamma} d E \\
= & \frac{\omega \alpha C}{Q_{a}} \int_{E=E_{a}}^{\infty} \sum_{J} \rho(E J) h\left(N_{a}(E J)\right. \\
& \left.+N_{b}(E J)\right) e^{-\beta E} e^{-\left(E-E_{a}\right) / \gamma} d E-k_{b i}^{0, b} \frac{Q_{b}}{Q_{a}},
\end{aligned}
$$

where $h(N)$ is again a unit step function. Since $a$ is the channel with the lower zero-point energy, $N_{a}(E J)$ is greater than $N_{b}(E J)$ for low-energy states. As a result, we can write $h\left(N_{a}(E J)+N_{b}(E J)\right)$ as $h\left(N_{a}(E J)\right)$ for these small $E$ 's. When $\Sigma_{J} \rho(E J) h\left(N_{a}(E J)\right)$ is again be assumed to be linearly depen- 
TABLE I. Relative rate constant coefficients for $\mathrm{X}+\mathrm{YZ} \rightarrow \mathrm{XYZ} / \mathrm{XY}+\mathrm{Z} \rightarrow \mathrm{XYZ}$ at low pressures and $300 \mathrm{~K}$.

\begin{tabular}{lcccc}
\hline \hline Reaction & $\Delta E_{0}\left(\mathrm{~cm}^{-1}\right)$ & Experiment $^{\mathrm{a}}$ & Calculated $^{\mathrm{b}}$ & Calculated $^{\mathrm{c}}$ \\
\hline${ }^{16} \mathrm{O}+{ }^{17} \mathrm{O}{ }^{17} \mathrm{O} /{ }^{17} \mathrm{O}+{ }^{17} \mathrm{O}^{16} \mathrm{O}$ & 11.9 & $\ldots$ & 2.62 & 2.65 \\
${ }^{16} \mathrm{O}+{ }^{18} \mathrm{O}{ }^{18} \mathrm{O} /{ }^{18} \mathrm{O}+{ }^{16} \mathrm{O}^{18} \mathrm{O}$ & 22.9 & 3.33 & 3.32 & 3.32 \\
${ }^{17} \mathrm{O}+{ }^{18} \mathrm{O}^{18} \mathrm{O} /{ }^{18} \mathrm{O}+{ }^{17} \mathrm{O}^{18} \mathrm{O}$ & 10.9 & $\ldots$ & 2.60 & 2.59 \\
${ }^{16} \mathrm{O}+{ }^{16} \mathrm{O}{ }^{17} \mathrm{O} /{ }^{17} \mathrm{O}+{ }^{16} \mathrm{O}^{16} \mathrm{O}$ & 11.7 & $\ldots$ & 0.66 & 0.65 \\
${ }^{16} \mathrm{O}+{ }^{16} \mathrm{O} \mathrm{O}^{18} \mathrm{O} /{ }^{18} \mathrm{O}+{ }^{16} \mathrm{O}^{16} \mathrm{O}$ & 22.3 & 0.82 & 0.81 & 0.81 \\
${ }^{17} \mathrm{O}+{ }^{17} \mathrm{O}{ }^{18} \mathrm{O} /{ }^{18} \mathrm{O}+{ }^{17} \mathrm{O} \mathrm{O}^{17} \mathrm{O}$ & 10.8 & $\ldots$ & 0.64 & 0.65 \\
${ }^{16} \mathrm{O}+{ }^{17} \mathrm{O}{ }^{18} \mathrm{O} /{ }^{18} \mathrm{O}+{ }^{16} \mathrm{O}^{17} \mathrm{O}$ & 22.6 & $\ldots$ & 1.56 & 1.63 \\
${ }^{17} \mathrm{O}+{ }^{16} \mathrm{O}{ }^{18} \mathrm{O} /{ }^{18} \mathrm{O}+{ }^{16} \mathrm{O}^{17} \mathrm{O}$ & 22.9 & $\cdots$ & 1.31 & 1.27 \\
\hline
\end{tabular}

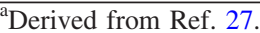

${ }^{\mathrm{b}}$ From Ref. 33 .

'Obtained using Eqs. (23a) and (23b).

dent on the excess energy $E$, Eq. (21) then becomes

$$
k_{b i}^{0, a}=\frac{\omega \alpha C C_{\rho}^{a}}{Q_{a} \beta^{\prime 2}} e^{-\beta E_{a}}-\frac{\omega \alpha C C_{\rho}^{b}}{2 Q_{a} \beta^{\prime 2}} e^{-\beta E_{b}} e^{-\left(\beta^{\prime} / 2+1 / \gamma\right) \Delta E_{0}} .
$$

If we define $R$ the rate constant ratio between $k_{b i}^{0, a}$ and $k_{b i}^{0, b}$,

$$
R \equiv \frac{k_{b i}^{0, a}}{k_{b i}^{0, b}}
$$

it can be obtained using Eqs. (20), (22), and (A3) to be

$$
R=\frac{Q_{b}}{Q_{a}}\left[2 e^{3 \beta^{\prime} \Delta E_{0} / 2}-1\right] .
$$

For the case of $k_{6.88} / k_{8.86}, \Delta E_{0}$ is about $23 \mathrm{~cm}^{-1}$ and the experimental value of the rate constant ratio at $300 \mathrm{~K}$ is about 3.33 (Table I). When Eqs. (23a) and (23b) is applied, it is found that $\gamma \approx 200 \mathrm{~cm}^{-1}$, which is very close to the values used in the detailed calculations. ${ }^{32}$

\section{Ratio of rate constants of $X+Y Y \rightarrow X Y Y$ and $X+X X$ $\rightarrow \mathrm{XXX}$}

In this section, the ratios of rate constants between $X$ $+\mathrm{YY} \rightarrow \mathrm{XYY}$ and $\mathrm{X}+\mathrm{XX} \rightarrow \mathrm{XXX}$ are calculated. An approximate expression for the formation rate constant for a symmetric molecule XXX is given by Eq. (A2). Using Eqs. (20) and (A2), the rate constant ratio between $X+Y Y$ $\rightarrow \mathrm{XYY}$ and $\mathrm{X}+\mathrm{XX} \rightarrow \mathrm{XXX}$ when the masses of $\mathrm{Y}, m_{\mathrm{Y}}$, is less than that of $\mathrm{X}, m_{\mathrm{X}}$, can be written as

$$
\frac{k_{X, Y Y}}{k_{X, X X}}=\frac{k_{Y, Y Y}}{k_{X, X X}} \eta e^{-\left(\beta^{\prime} / 2+1 / \gamma\right) \Delta E_{0},}
$$

and when $m_{\mathrm{Y}}>m_{\mathrm{X}}$ it is instead

$$
\frac{k_{X, Y Y}}{k_{X, X X}}=\frac{k_{Y, Y Y}}{k_{X, X X}} \eta\left(2-e^{3 \beta^{\prime} / 2 \Delta E_{0}}\right) .
$$

These rate constant ratios are then calculated and compared in Table II with previous theoretical results and experimental results. An $\eta=1.18$ was used in applying Eqs. (24) and (25).

\section{E. Application to other systems}

Equation (22) is also applied to some other systems of atmospheric or geochemical interest, such as $\mathrm{CO}_{2}, \mathrm{ClO}_{2}$, $\mathrm{SiO}_{2}, \mathrm{SO}_{2}, \mathrm{NO}_{2}$, and $\mathrm{AlO}_{2}$. We are particularly interested in the rate constant ratios between the two channels for the formation of these molecules, when the two oxygen atoms are different isotopes. The rate constant ratio between channels $a$ and $b$ can then be calculated using Eq. (25). The differences in zero-point energies are taken from Ref. 40. The energy transfer parameter $\gamma$ is taken as the same as that for ozone for each of these molecules. The actual value for each individual system should be obtained by direct energy transfer experiments or by fitting to rate constant ratios as done for ozone in Refs. 33 and 34. The predicted values for the rate constant ratios are given in Table III.

In this calculation of the ratios of rates and of the MIF for other reactions, some of which may be "spin forbidden," we should consider whether the odd spin of ${ }^{17} \mathrm{O}$ would affect the reaction rate. At first glance a potential objection to observing a MIF in a reaction such as $\mathrm{CO}+\mathrm{O} \rightarrow \mathrm{CO}_{2}^{*}$, an objection that is easily removed, however, is that the desired reaction is electronically spin forbidden (singlet $\mathrm{CO}$ + triplet $\mathrm{O} \rightarrow$ singlet $\mathrm{CO}_{2}$ ). The presence of an odd numbered nucleus ${ }^{17} \mathrm{O}$ in a reactant reduces the spin-forbidden impediment for this reaction due to electron spin-nuclear spin coupling, and so catalyzes the recombination and destroys any mass independence. However, this effect would occur both in the formation, $\mathrm{CO}+\mathrm{O} \rightarrow \mathrm{CO}_{2}^{*}$, and in the redissociation, $\mathrm{CO}_{2}^{*} \rightarrow \mathrm{CO}+\mathrm{O}$, of the $\mathrm{CO}_{2}^{*}$. Since the redissociation of the $\mathrm{CO}_{2}^{*}$ dominates over collisional stabilization of the $\mathrm{CO}_{2}^{*}$ at low pressures, this spin-spin effect favoring formation of $\mathrm{CO}_{2}^{*}$ containing ${ }^{17} \mathrm{O}$ also favors this reverse process and so the effect cancels at low pressures. At sufficiently high pressures, however, pressures not relevant here, there would be little redissociation of the $\mathrm{CO}_{2}^{*}$ because of collisional deac-

TABLE II. Relative rate constant coefficients for $\mathrm{X}+\mathrm{YY} \rightarrow \mathrm{XYY}$ relative to $\mathrm{X}+\mathrm{XX} \rightarrow \mathrm{XXX}$ at low pressures and $300 \mathrm{~K}$.

\begin{tabular}{lccc}
\hline \hline Reaction & Experiment $^{\mathrm{a}}$ & Calculated $^{\mathrm{b}}$ & Calculated $^{\mathrm{c}}$ \\
\hline${ }^{16} \mathrm{O}+{ }^{18} \mathrm{O}^{18} \mathrm{O} /{ }^{16} \mathrm{O}+{ }^{16} \mathrm{O}^{16} \mathrm{O}$ & $1.53 \pm 0.03$ & 1.53 & 1.55 \\
${ }^{17} \mathrm{O}+{ }^{18} \mathrm{O}^{18} \mathrm{O} /{ }^{17} \mathrm{O}+{ }^{17} \mathrm{O}^{17} \mathrm{O}$ & $1.29 \pm 0.07$ & 1.36 & 1.36 \\
${ }^{16} \mathrm{O}+{ }^{17} \mathrm{O}^{17} \mathrm{O} /{ }^{16} \mathrm{O}+{ }^{16} \mathrm{O}^{16} \mathrm{O}$ & $1.23 \pm 0.03$ & 1.38 & 1.39 \\
${ }^{17} \mathrm{O}+{ }^{16} \mathrm{O}^{16} \mathrm{O} /{ }^{17} \mathrm{O}+{ }^{17} \mathrm{O}^{17} \mathrm{O}$ & $1.01 \pm 0.05$ & 1.01 & 1.03 \\
${ }^{18} \mathrm{O}+{ }^{17} \mathrm{O}^{17} \mathrm{O} /{ }^{18} \mathrm{O}+{ }^{18} \mathrm{O}^{18} \mathrm{O}$ & $1.00 \pm 0.06$ & 1.04 & 1.04 \\
${ }^{18} \mathrm{O}+{ }^{16} \mathrm{O}^{16} \mathrm{O} /{ }^{18} \mathrm{O}+{ }^{18} \mathrm{O}^{18} \mathrm{O}$ & $0.90 \pm 0.03$ & 0.90 & 0.91 \\
\hline
\end{tabular}

${ }^{\mathrm{a}}$ From Ref. 26

${ }^{\mathrm{b}}$ From Ref. 33.

'Obtained using Eqs. (24) and (25), $\eta=1.18$. 
TABLE III. Predicted relative rate constant coefficients for $\mathrm{X}+\mathrm{AY}$ $\rightarrow \mathrm{XAY} / \mathrm{Y}+\mathrm{AX} \rightarrow \mathrm{XAY}$ at low pressures and $300 \mathrm{~K}$.

\begin{tabular}{|c|c|c|}
\hline Reaction & $\Delta E_{0} \quad\left(\mathrm{~cm}^{-1}\right)^{\mathrm{a}}$ & Calculated rate constant ratio \\
\hline${ }^{16} \mathrm{O}+{ }^{27} \mathrm{Al}{ }^{18} \mathrm{O} /{ }^{18} \mathrm{O}+{ }^{27} \mathrm{O}{ }^{16} \mathrm{O}$ & 17.4 & 1.46 \\
\hline${ }^{16} \mathrm{O}+{ }^{27} \mathrm{Al}^{17} \mathrm{O} /{ }^{17} \mathrm{O}+{ }^{27} \mathrm{Al}^{16} \mathrm{O}$ & 9.1 & 1.23 \\
\hline${ }^{17} \mathrm{O}+{ }^{27} \mathrm{Al}{ }^{18} \mathrm{O} /{ }^{18} \mathrm{O}+{ }^{27} \mathrm{Al}{ }^{17} \mathrm{O}$ & 8.2 & 1.21 \\
\hline${ }^{16} \mathrm{O}+{ }^{12} \mathrm{C}^{18} \mathrm{O} /{ }^{18} \mathrm{O}+{ }^{12} \mathrm{C}^{16} \mathrm{O}$ & 26.1 & 1.71 \\
\hline${ }^{16} \mathrm{O}+{ }^{12} \mathrm{C}^{17} \mathrm{O} /{ }^{17} \mathrm{O}+{ }^{12} \mathrm{C}^{16} \mathrm{O}$ & 13.8 & 1.36 \\
\hline${ }^{17} \mathrm{O}+{ }^{12} \mathrm{C}^{18} \mathrm{O} /{ }^{18} \mathrm{O}+{ }^{12} \mathrm{C}^{17} \mathrm{O}$ & 12.4 & 1.32 \\
\hline${ }^{16} \mathrm{O}+{ }^{13} \mathrm{C}^{18} \mathrm{O} /{ }^{18} \mathrm{O}+{ }^{13} \mathrm{C}^{16} \mathrm{O}$ & 27.4 & 1.75 \\
\hline${ }^{16} \mathrm{O}+{ }^{13} \mathrm{C}^{17} \mathrm{O} /{ }^{17} \mathrm{O}+{ }^{13} \mathrm{C}^{16} \mathrm{O}$ & 14.4 & 1.38 \\
\hline${ }^{17} \mathrm{O}+{ }^{13} \mathrm{C}^{18} \mathrm{O} /{ }^{18} \mathrm{O}+{ }^{13} \mathrm{C}^{17} \mathrm{O}$ & 13.0 & 1.34 \\
\hline${ }^{16} \mathrm{O}+{ }^{35} \mathrm{Cl}{ }^{18} \mathrm{O} /{ }^{18} \mathrm{O}+{ }^{35} \mathrm{Cl}^{16} \mathrm{O}$ & 16.6 & 1.44 \\
\hline${ }^{16} \mathrm{O}+{ }^{35} \mathrm{Cl}{ }^{17} \mathrm{O} /{ }^{17} \mathrm{O}+{ }^{35} \mathrm{Cl}{ }^{16} \mathrm{O}$ & 8.7 & 1.22 \\
\hline${ }^{17} \mathrm{O}+{ }^{35} \mathrm{Cl}{ }^{18} \mathrm{O} /{ }^{18} \mathrm{O}+{ }^{35} \mathrm{Cl}^{17} \mathrm{O}$ & 7.9 & 1.20 \\
\hline${ }^{16} \mathrm{O}+{ }^{14} \mathrm{~N}^{18} \mathrm{O} /{ }^{18} \mathrm{O}+{ }^{14} \mathrm{~N}^{16} \mathrm{O}$ & 25.0 & 1.68 \\
\hline${ }^{16} \mathrm{O}+{ }^{14} \mathrm{~N}{ }^{17} \mathrm{O} /{ }^{17} \mathrm{O}+{ }^{14} \mathrm{~N}^{16} \mathrm{O}$ & 13.2 & 1.34 \\
\hline${ }^{17} \mathrm{O}+{ }^{14} \mathrm{~N}{ }^{18} \mathrm{O} /{ }^{18} \mathrm{O}+{ }^{14} \mathrm{~N}^{17} \mathrm{O}$ & 11.9 & 1.30 \\
\hline${ }^{16} \mathrm{O}+{ }^{32} \mathrm{~S}{ }^{18} \mathrm{O} /{ }^{18} \mathrm{O}+{ }^{32} \mathrm{~S}{ }^{16} \mathrm{O}$ & 21.7 & 1.58 \\
\hline${ }^{16} \mathrm{O}+{ }^{32} \mathrm{~S}{ }^{17} \mathrm{O} /{ }^{17} \mathrm{O}+{ }^{32} \mathrm{~S}{ }^{16} \mathrm{O}$ & 11.4 & 1.29 \\
\hline${ }^{17} \mathrm{O}+{ }^{32} \mathrm{~S}{ }^{18} \mathrm{O} /{ }^{18} \mathrm{O}+{ }^{32} \mathrm{~S}{ }^{17} \mathrm{O}$ & 10.3 & 1.26 \\
\hline${ }^{16} \mathrm{O}+{ }^{28} \mathrm{Si}^{18} \mathrm{O} /{ }^{18} \mathrm{O}+{ }^{28} \mathrm{Si}^{16} \mathrm{O}$ & 22.4 & 1.60 \\
\hline${ }^{16} \mathrm{O}+{ }^{28} \mathrm{Si}^{17} \mathrm{O} /{ }^{17} \mathrm{O}+{ }^{28} \mathrm{Si}^{16} \mathrm{O}$ & 11.7 & 1.30 \\
\hline${ }^{17} \mathrm{O}+{ }^{28} \mathrm{Si}^{18} \mathrm{O} /{ }^{18} \mathrm{O}+{ }^{28} \mathrm{Si}^{17} \mathrm{O}$ & 10.6 & 1.27 \\
\hline
\end{tabular}

${ }^{\mathrm{a}}$ From Ref. 41.

tivation, and then the spin-spin coupling would indeed favor ${ }^{17} \mathrm{O}$ enrichment in the $\mathrm{CO}_{2}$ or in any of the other examples considered below.

\section{PRESSURE EFFECTS ON RATE CONSTANT RATIOS AND ON ENRICHMENTS}

\section{A. Pressure dependence of rate constant ratios}

To study the pressure dependence, an effective macroscopic kinetic scheme for the reactions will be used. The formation of ${ }^{16} \mathrm{O}^{16} \mathrm{O}^{18} \mathrm{O}$ will be used as an example. Its formation via channel $a$ can be written as

$$
\begin{aligned}
& { }^{16} \mathrm{O}+{ }^{16} \mathrm{O}^{18} \mathrm{O} \stackrel{{ }^{k}}{\longrightarrow}{ }^{16} \mathrm{O}^{16} \mathrm{O}^{18} \mathrm{O}^{*}, \\
& { }^{16} \mathrm{O}^{16} \mathrm{O}^{18} \mathrm{O}^{*} \stackrel{{ }_{a}^{\prime}}{\longrightarrow}{ }^{16} \mathrm{O}+{ }^{16} \mathrm{O}^{18} \mathrm{O}, \\
& { }^{16} \mathrm{O}^{16} \mathrm{O}^{18} \mathrm{O}^{*} \stackrel{{ }_{b}^{\prime}}{\longrightarrow}{ }^{18} \mathrm{O}+{ }^{16} \mathrm{O}^{16} \mathrm{O}, \\
& { }^{16} \mathrm{O}^{16} \mathrm{O}^{18} \mathrm{O}^{*} \stackrel{{ }^{\omega}}{\longrightarrow}{ }^{16} \mathrm{O}^{16} \mathrm{O}^{18} \mathrm{O},
\end{aligned}
$$

where $k_{a}, k_{a}^{\prime}$, and $k_{b}^{\prime}$ are phenomenological recombination and dissociation rate constants, and $\omega$ is the rate constant for the deactivation of excited molecules ${ }^{16} \mathrm{O}^{16} \mathrm{O}^{18} \mathrm{O}^{*}$ to form stable molecules. The rate constant for the formation of ${ }^{16} \mathrm{O}^{16} \mathrm{O}^{18} \mathrm{O}$ via this channel can then be written as

$$
k_{b i}^{a}=\frac{\omega k_{a}}{k_{a}^{\prime}+k_{b}^{\prime}+\omega} .
$$

The low- and high-pressure limits of Eq. (30) are

$$
k_{b i}^{0, a}=\frac{\omega k_{a}}{k_{a}^{\prime}+k_{b}^{\prime}}, \quad k_{b i}^{\infty, a}=k_{a},
$$

respectively. The formation reaction of ${ }^{16} \mathrm{O}^{16} \mathrm{O}^{18} \mathrm{O}$ via its channel $b$ can be written in a similar way,

$$
\begin{gathered}
{ }^{18} \mathrm{O}+{ }^{16} \mathrm{O}^{16} \mathrm{O} \stackrel{{ }_{b}}{\longrightarrow}{ }^{16} \mathrm{O}^{16} \mathrm{O}^{18} \mathrm{O}^{*} \\
{ }^{16} \mathrm{O}^{16} \mathrm{O}^{18} \mathrm{O}^{*} \stackrel{{ }^{\prime \prime}}{\longrightarrow}{ }^{16} \mathrm{O}+{ }^{16} \mathrm{O}^{18} \mathrm{O}, \\
{ }^{16} \mathrm{O}^{16} \mathrm{O}^{18} \mathrm{O}^{*} \stackrel{{ }_{b}^{\prime \prime}}{\longrightarrow}{ }^{18} \mathrm{O}+{ }^{16} \mathrm{O}^{16} \mathrm{O}, \\
{ }^{16} \mathrm{O}^{16} \mathrm{O}^{18} \mathrm{O}^{*} \stackrel{{ }^{\omega}}{\longrightarrow}{ }^{16} \mathrm{O}^{16} \mathrm{O}^{18} \mathrm{O},
\end{gathered}
$$

where the rate constants are defined similarly as in Eqs. (26)-(29). It should be noted that since the recombination via channel $b$ leads to ozone molecules with an averaged energy higher than those formed from channel $a$, the dissociation rate constants $k_{a}^{\prime \prime}$ and $k_{b}^{\prime \prime}$ are greater than $k_{a}^{\prime}$ and $k_{b}^{\prime}$, respectively. The rate constant for the recombination reaction via channel $b$ is then

$$
k_{b i}^{b}=\frac{\omega k_{b}}{k_{a}^{\prime \prime}+k_{b}^{\prime \prime}+\omega},
$$

the low and high pressure limits of which are

$$
k_{b i}^{0, b}=\frac{\omega k_{b}}{k_{a}^{\prime \prime}+k_{b}^{\prime \prime}}, \quad k_{b i}^{\infty, b}=k_{b} .
$$

For a symmetric molecule ${ }^{16} \mathrm{O}^{16} \mathrm{O}^{16} \mathrm{O}$, the recombination rate constant can be similarly written as

$$
k_{b i}^{s}=\frac{\omega k_{s}}{k_{s}^{\prime}+\omega}, \quad k_{b i}^{0, s}=\frac{\omega k_{s}}{k_{s}^{\prime}}, \quad k_{b i}^{\infty, b}=k_{s} .
$$

Under the approximations that the conventional kinetic isotopic effects at high pressure are small,

$$
\frac{k_{b i}^{\infty, a}}{\sigma_{a}} \approx \frac{k_{b i}^{\infty, b}}{\sigma_{b}} \approx \frac{k_{b i}^{\infty, s}}{\sigma_{s}},
$$

where $\sigma_{s}$ is the symmetry number of $\mathrm{O}_{2}$ and equals 2 , and using $k_{b i}^{0, a} / k_{b i}^{0, b}=R$ [Eqs. (23a) and (23b)] and Eqs. (30), (31), and (36)-(39), the rate constant ratios can be written as

$$
\frac{k_{b i}^{b}}{k_{b i}^{s}}=\eta \sigma_{a} \sigma_{h} \frac{1+\omega / k_{s}^{\prime}}{\left(R+Q_{b} / Q_{a}\right) \sigma_{b}+\eta \sigma_{s} \sigma_{a} \omega / k_{s}^{\prime}}
$$

and

$$
\frac{k_{b i}^{a}}{k_{b i}^{s}}=\eta \sigma_{a} \frac{1+\omega / k_{s}^{\prime}}{\left(1+Q_{b} / R Q_{a}\right) \sigma_{b}+\eta \sigma_{s} \omega / k_{s}^{\prime}} .
$$

For example, we have $\sigma_{a}=1$ and $\sigma_{b}=\sigma_{s}=2$ for the rate constant ratio between ${ }^{18} \mathrm{O}+{ }^{16} \mathrm{O}^{16} \mathrm{O} \rightarrow{ }^{16} \mathrm{O}^{16} \mathrm{O}^{18} \mathrm{O}$ and ${ }^{16} \mathrm{O}$ $+{ }^{16} \mathrm{O}^{16} \mathrm{O} \rightarrow{ }^{16} \mathrm{O}^{16} \mathrm{O}^{16} \mathrm{O}$, and Eq. (40) reduces to

$$
\frac{k_{b i}^{b}}{k_{b i}^{s}}=\frac{1+\omega / k_{s}^{\prime}}{\left(R+Q_{b} / Q_{a}\right) / \eta+\omega / k_{s}^{\prime}} .
$$


For the case of ${ }^{16} \mathrm{O}+{ }^{18} \mathrm{O}^{18} \mathrm{O} \rightarrow{ }^{16} \mathrm{O}^{18} \mathrm{O}^{18} \mathrm{O}$ and ${ }^{18} \mathrm{O}$ $+{ }^{18} \mathrm{O}^{18} \mathrm{O} \rightarrow{ }^{18} \mathrm{O}^{18} \mathrm{O}^{18} \mathrm{O}$, we have

$$
\frac{k_{b i}^{a}}{k_{b i}^{s}}=\frac{1+\omega / k_{s}^{\prime}}{\left(1+Q_{b} / R Q_{a}\right) / 2 \eta+\omega / k_{s}^{\prime}} .
$$

\section{B. Pressure dependence of enrichment ${ }^{18} \delta$}

The pressure dependence of the enrichments in a scrambled system such as ${ }^{16} \mathrm{O}^{18} \mathrm{O}^{16} \mathrm{O}+{ }^{16} \mathrm{O}^{16} \mathrm{O}^{18} \mathrm{O}$ will be considered in the following. The kinetic scheme for the formation of ozone with the presence of small amount of ${ }^{16} \mathrm{O}^{18} \mathrm{O}$ in the system as is typically the case for the atmosphere can be written as in Appendix B. Using steady-state approximations, the enrichment ${ }^{18} \delta$ becomes

$$
{ }^{18} \delta=\frac{2}{3} \frac{\left[{ }^{16} \mathrm{O}^{18} \mathrm{O}^{16} \mathrm{O}^{*}\right]+\left[{ }^{16} \mathrm{O}^{16} \mathrm{O}^{18} \mathrm{O}^{*}\right]}{\left[{ }^{16} \mathrm{O}^{16} \mathrm{O}^{16} \mathrm{O}^{*}\right]} / \frac{\left[{ }^{16} \mathrm{O}^{18} \mathrm{O}\right]}{\left[{ }^{16} \mathrm{O}^{16} \mathrm{O}\right]}-1 .
$$

Using the relation given in Eq. (39) and also $k_{s} \approx k_{b} / 2$ [see Eqs. (37) and (38)], and noting that $k_{b} k_{a} / k_{a}^{\prime} k_{b}=Q_{b} / Q_{a}$, Eq. (44) becomes

$$
{ }^{18} \delta=\frac{\eta-1}{1+2 \eta \omega / k_{s}^{\prime}} .
$$

If one writes the low-pressure limit of ${ }^{18} \delta$ as ${ }^{18} \delta_{0}$, Eq. (45) can be further written as

$$
{ }^{18} \delta=\frac{{ }^{18} \delta_{0}}{1+P / P_{1 / 2}},
$$

where $P_{1 / 2}$ is the pressure at which takes one-half of the value of its low-pressure limit. This expression has been assumed in Ref. 27, and the $P_{1 / 2}$ can be obtained by fitting the experimental results of enrichment.

The rate constant ratios given in Eqs. (42) and (43) can also be expressed in terms of $P_{1 / 2}$, for example,

$$
\frac{k_{6,88}}{k_{8,88}}=\frac{2 \eta+P / 2 P_{1 / 2}}{\left(1+Q_{68} / R Q_{88}\right)+P / 2 P_{1 / 2}}
$$

and

$$
\frac{k_{8,66}}{k_{6,66}}=\frac{\eta+P / 2 P_{1 / 2}}{R+Q_{66} / Q_{68}+P / 2 P_{1 / 2}} .
$$

The fitted pressure dependence of the enrichment is compared with the experimental results in Fig. 1 . The fitted $P_{1 / 2}$ was then applied in Eqs. (47) and (48) and yielded the pressure dependence of which are compared with the experimental results in Fig. 2.

\section{DISCUSSION}

In the present study, an approximate theory was developed for the ozone isotopic effect. Analytic expressions were obtained for the low-pressure rate constant ratios and for the pressure dependence of the rate constant ratios and of the enrichments. The nonstatistical difference between the rates of formation of symmetric and asymmetric ozone molecules was termed an $\eta$-effect and discussed earlier. This $\eta$-effect is

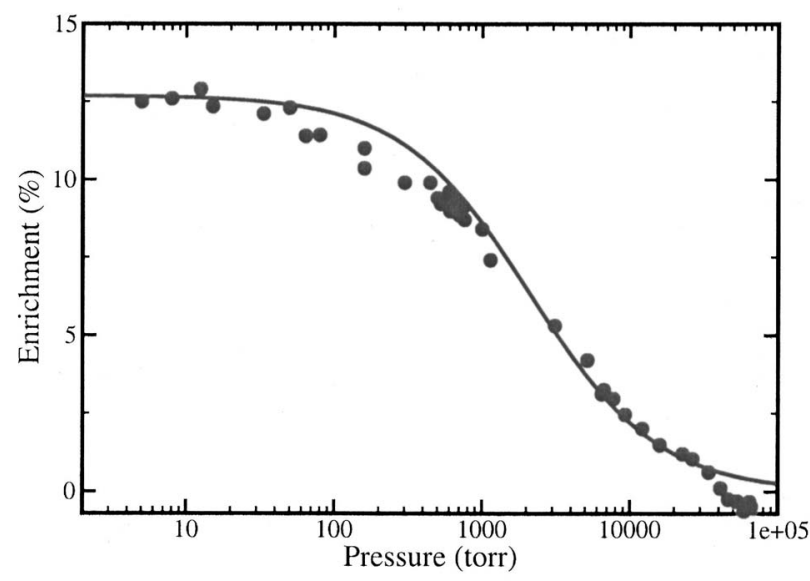

FIG. 1. The comparison between the calculated ${ }^{18} \delta$ as a function of pressure in comparison with experimental results (experimental data from Ref. 28).

also included in the present study as a reduction of the recombination rate constant of symmetric molecule compared to asymmetric products. One focus of the present research is the rate constant ratios between the formation channels $X$ $+\mathrm{YZ}(a)$ and $\mathrm{Z}+\mathrm{YX}(b)$ of an asymmetric molecule $\mathrm{XYZ}$ $(X \neq Z)$, for which the $\eta$-effect does not exist. To calculate the recombination rate constant, an approximate RRKM theory modified by the $\eta$ effect was used, where, based on earlier calculations, the number of states at the transition state was assumed to be a linear function of energy. As seen from Eqs. (23a) and (23b), the two factors that determine the low-pressure rate constant ratios between $a$ and $b$ channels are the zero-point energy difference between $\mathrm{YZ}$ and $\mathrm{YX}$ and the efficiency of the collisional deactivation of excited XYZ.

At any given energy, this difference of the zero-point energies favors the reaction through the channel with the smaller zero-point energy because of the greater number of quantum states in the transition state for that exit channel. This difference between the numbers of states at the transition states for the two exit channels is large at low energies.

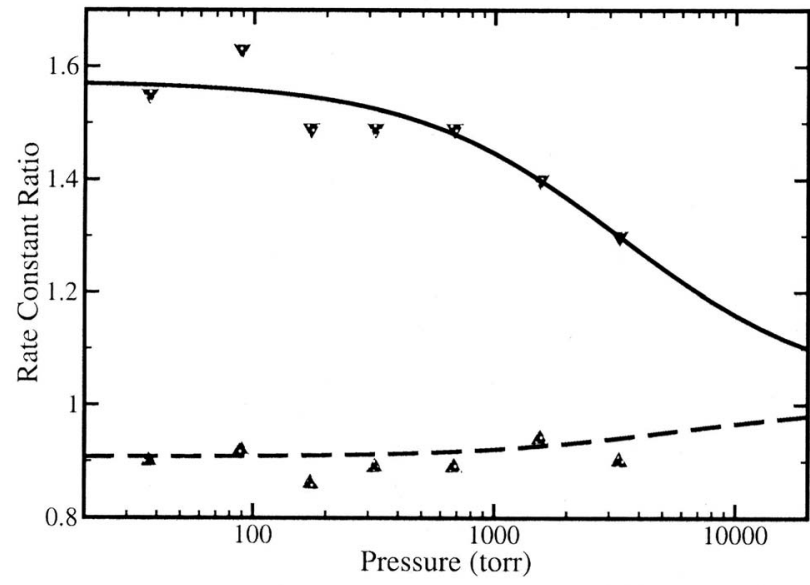

FIG. 2. The calculated pressure dependence of the rate constant ratio for ${ }^{16} \mathrm{O}+{ }^{18} \mathrm{O}{ }^{18} \mathrm{O} /{ }^{16} \mathrm{O}+{ }^{16} \mathrm{O}{ }^{16} \mathrm{O}$ (calculated; solid line; experimental data; downward triangles), and for ${ }^{18} \mathrm{O}+{ }^{16} \mathrm{O}{ }^{16} \mathrm{O} /{ }^{18} \mathrm{O}+{ }^{18} \mathrm{O}{ }^{18} \mathrm{O}$ (calculated; dash line; experimental data; upward triangles). The experimental data are taken from Ref. 28. 
Since weak collisions sample mainly low energy states, a large difference between the rate constants for reactions via the two recombination channels for XYZ arises at low pressures. The effect of the difference in zero-point energies and the weak collision can be readily seen from Eqs. (23a) and (23b). They contribute together to the exponent $-\left(\beta^{\prime} / 2\right.$ $+1 / \gamma) \Delta E_{0}$. If a strong collision model was assumed, one would instead have for the rate constant ratio,

$$
R=2 e^{3 \beta \Delta E_{0} / 2} Q_{b} / Q_{a}-Q_{b} / Q_{a} .
$$

It is seen from the comparison of Eqs. (23a), (23b), and (49) that the weak collision is essential for the large difference between the rates of recombination via channels $a$ and $b$.

Since the zero-point energy difference between $\mathrm{YZ}$ and YX depends mainly on the mass difference between $\mathrm{Z}$ and $X$, this weak collision effect leads to a large mass dependence of individual rate constant ratios measured under conditions of unscrambled systems, where only reaction via one of the two channels occurs. For example, in unscrambled experiments vibrationally excited ozone isotopomers $X Y Y^{*}$ are formed only from $\mathrm{X}+\mathrm{YY}$ and not from $\mathrm{Y}+\mathrm{YX}$. In a scrambled system, since both channels are allowed in the formation of $\mathrm{XYY}^{*}$, this source of mass dependence does not exist. What remains is the $\eta$-effect. As discussed in earlier papers, the $\eta$-effect could be a result of a smaller effective density of states or a less efficiency of the collisional energy transfer for symmetric ozone molecules. Both effects yield a smaller rate constant for the formation of symmetric ozone molecules at low pressures. As pressure increases, the influence of the $\eta$-effect decreases, and so does the enrichment, as shown in Eq. (45) and Fig. 1.

Since the probability of ozone states with higher energies above the dissociation threshold being deactivated increases with pressure, at higher pressures the rate constant ratios between the formation via $a$ and $b$ channels become smaller. This effect then also tends to decrease the ratio between the rate constant of the formation of an asymmetric molecule via channel $a$ and that of formation of a symmetric molecule and increase the ratio between the formation rate constant for channel $b$ of the asymmetric molecule and that for the symmetric one. Reinforced with the decrease of the $\eta$-effect, the pressure increase results in a decrease of the ratio of rate constant of formation of an asymmetric molecule via channel $a$ and formation of a symmetric molecule. In contrast, the ratio of rate constants of formation of asymmetric molecules via channel $b$ and the formation of symmetric molecules remains almost constant in a large pressure range because the two effects mentioned above affect this rate constant ratio in opposite directions.

The present study yields simple formulas for the rate constant ratios between individual rate constants that can be tested by experiments. Although these formulas do not provide a simple way of calculating the absolute rate constant, they can be used to estimate rate constant for asymmetric reactions such as ${ }^{16} \mathrm{O}+{ }^{18} \mathrm{O}^{18} \mathrm{O} \rightarrow{ }^{16} \mathrm{O}^{18} \mathrm{O}^{18} \mathrm{O}$ if the rate constant for ${ }^{16} \mathrm{O}+{ }^{16} \mathrm{O}^{16} \mathrm{O} \rightarrow{ }^{16} \mathrm{O}^{16} \mathrm{O}^{16} \mathrm{O}$ or ${ }^{18} \mathrm{O}+{ }^{16} \mathrm{O}{ }^{18} \mathrm{O}$ $\rightarrow{ }^{18} \mathrm{O}^{16} \mathrm{O}^{18} \mathrm{O}$ is known (certainly the former of the two is easier to be obtained experimentally).

\section{ACKNOWLEDGMENTS}

It is a pleasure to acknowledge the support of this research by the Dreyfus Foundation (Y.Q.G) and the National Science Foundation (R.A.M). Y.Q.G is a 2006 Searle Scholar.

\section{APPENDIX A: RATE CONSTANT FOR THE FORMATION OF SYMMETRIC MOLECULES}

In this appendix, we obtain an expression for the rate constant of the formation of a symmetric ozone molecule XYX at low pressures. Similar to Eq. (14), such a rate constant can be written as

$$
k_{b i}^{0, s}=\frac{\omega \alpha C}{\eta Q_{X, Y X}} \int_{E=0}^{o}\left[\sum_{J} \rho(E J) h(N(E J))\right] e^{-\beta E} e^{-\left(E-E_{S}\right) / \gamma} d E,
$$

where $E_{s}$ is the zero-point energy of XY. Using an approximation that $\Sigma_{J} \rho(E J) h(N(E J))=C_{p}^{X Y X}\left(E-E_{X Y}\right)$, where $C_{\rho}^{X Y X}$ is a constant determined mainly by the moment of inertia of $\mathrm{XY}$ [we note here that due to the different symmetry number of $\mathrm{XYY}$ and $\left.\mathrm{XXX}(\mathrm{X} \neq \mathrm{Y}), C_{\rho}^{X Y Y} \approx 2 C_{\rho}^{X X X}\right]$ and $E_{X Y}$ is the zero-point energy of the fragment $X Y$, Eq. (A1) can be written as

$$
k_{b i}^{0, s}=\frac{\omega C C_{\rho}^{X Y X}}{\eta \beta^{\prime 2} Q_{X, Y X}} e^{-\beta E_{X Y}} .
$$

As can be seen from both experimental and calculated ratios between the rate constants for the formation of symmetric molecules (Table III of Ref. 33), the rate constants for formation of the symmetric molecules differ from each other only by a few percent. Further, since $Q_{X, Y X}$ and $Q_{Z, Y X}$ for different $\mathrm{X}$ and $\mathrm{Z}$ differ only in their translational components and are close to each other, one has an approximate relation

$$
\frac{\omega C C_{\rho}^{X Y Z}}{\sigma_{X Y} Q_{Z, Y X}} e^{-\beta E_{X Y}} \approx \text { constant }
$$

where $\mathrm{Z}$ may or may not be the same as $\mathrm{X}$ and $\sigma_{X Y}$ is the symmetry number of $X Y$. This relation is used in deriving expressions for rate constant ratios.

\section{APPENDIX B: CHEMICAL REACTIONS IN A SCRAMBLED SYSTEM}

$$
{ }^{16} \mathrm{O}{ }^{16} \mathrm{O} \longrightarrow{ }^{h \nu} \longrightarrow{ }^{16} \mathrm{O}+{ }^{16} \mathrm{O}, \quad{ }^{16} \mathrm{O}^{18} \mathrm{O} \longrightarrow{ }^{h \nu} \longrightarrow{ }^{16} \mathrm{O}+{ }^{18} \mathrm{O},
$$

where $h \nu$ is the photodissociation rate constant. And recombination of the oxygen radicals is neglected due to their low concentrations compared to $\mathrm{O}_{2}$. In the presence of ${ }^{16} \mathrm{O}^{16} \mathrm{O}$, ${ }^{16} \mathrm{O}^{18} \mathrm{O}$, ${ }^{16} \mathrm{O}$, and ${ }^{18} \mathrm{O}$ (with negligible amount of ${ }^{18} \mathrm{O}{ }^{18} \mathrm{O}$ ), the recombination and dissociation reactions are as follows:

$$
\begin{aligned}
& { }^{18} \mathrm{O}+{ }^{16} \mathrm{O}^{16} \mathrm{O} \stackrel{{ }_{a}}{\longrightarrow}{ }^{16} \mathrm{O}^{16} \mathrm{O}^{18} \mathrm{O}{ }^{*} \\
& { }^{16} \mathrm{O}^{16} \mathrm{O}^{18} \mathrm{O}^{*} \stackrel{k_{a}^{\prime}}{\longrightarrow}{ }^{16} \mathrm{O}+{ }^{16} \mathrm{O}^{18} \mathrm{O},
\end{aligned}
$$




$$
\begin{aligned}
& { }^{16} \mathrm{O}^{16} \mathrm{O}^{18} \mathrm{O}^{*} \stackrel{{ }_{b}^{\prime}}{\longrightarrow}{ }^{18} \mathrm{O}+{ }^{16} \mathrm{O}^{16} \mathrm{O}, \\
& { }^{16} \mathrm{O}^{16} \mathrm{O}^{18} \mathrm{O}^{*} \stackrel{{ }^{\omega}}{\longrightarrow}{ }^{16} \mathrm{O}^{16} \mathrm{O}^{18} \mathrm{O}, \\
& { }^{16} \mathrm{O}+{ }^{16} \mathrm{O}^{16} \mathrm{O} \stackrel{{ }_{b}}{\longrightarrow}{ }^{16} \mathrm{O}^{16} \mathrm{O}^{16} \mathrm{O}^{*}, \\
& { }^{16} \mathrm{O}^{16} \mathrm{O}^{16} \mathrm{O}^{*} \stackrel{{ }_{b}^{\prime}}{\longrightarrow}{ }^{16} \mathrm{O}+{ }^{16} \mathrm{O}^{16} \mathrm{O}, \\
& { }^{16} \mathrm{O}^{16} \mathrm{O}^{16} \mathrm{O}^{*} \stackrel{{ }^{\omega}}{\longrightarrow}{ }^{16} \mathrm{O}^{16} \mathrm{O}^{16} \mathrm{O}, \\
& { }^{16} \mathrm{O}+{ }^{16} \mathrm{O}^{18} \mathrm{O} \stackrel{{ }_{s}}{\longrightarrow}{ }^{16} \mathrm{O}^{18} \mathrm{O}^{16} \mathrm{O}^{*}, \\
& { }^{16} \mathrm{O}^{18} \mathrm{O}^{16} \mathrm{O}^{*} \stackrel{{ }_{s}^{\prime}}{\longrightarrow}{ }^{16} \mathrm{O}+{ }^{16} \mathrm{O}^{18} \mathrm{O}, \\
& { }^{16} \mathrm{O}^{18} \mathrm{O}^{16} \mathrm{O}^{*} \stackrel{{ }^{\omega}}{\longrightarrow}{ }^{16} \mathrm{O}^{18} \mathrm{O}^{16} \mathrm{O} .
\end{aligned}
$$

${ }^{1}$ Clayton, L. Grossman, and T. K. Mayeda, Science 182, 485 (1973).

${ }^{2}$ J. E. Heidenreic III and M. H. Thiemens, J. Chem. Phys. 78, 892 (1983).

${ }^{3}$ J. E. Heidenreic III and M. H. Thiemens, J. Chem. Phys. 84, 2129 (1986).

${ }^{4}$ K. Mauersberger, Geophys. Res. Lett. 14, 80 (1987).

${ }^{5}$ J. Yang and S. Epstein, Geochim. Cosmochim. Acta 51, 2011 (1987).

${ }^{6}$ J. Yang and S. Epstein, Geochim. Cosmochim. Acta 51, 2019 (1987).

${ }^{7}$ M. H. Thiemens and T. Jackson, Geophys. Res. Lett. 14, 624 (1987).

${ }^{8}$ M. H. Thiemens and T. Jackson, Geophys. Res. Lett. 15, 639 (1988).

${ }^{9}$ S. M. Anderson, J. Morton, and K. Mauersberger, Chem. Phys. Lett. 156, 175 (1989).

${ }^{10}$ J. Morton, B. Schueler, and K. Mauersberger, Chem. Phys. Lett. 154, 143 (1989).

${ }^{11}$ J. Morton, J. Barnes, B. Schueler, and K. Mauersberger, J. Geophys. Res. 95, 901 (1990).

${ }^{12}$ M. H. Thiemens and T. Jackson, Geophys. Res. Lett. 17, 717 (1990).
${ }^{13}$ B. Schueler, J. Morton, and K. Mauersberger, Geophys. Res. Lett. 17, 1295 (1990)

${ }^{14}$ J. Wen and M. H. Thiemens, Chem. Phys. Lett. 172, 416 (1990).

${ }^{15}$ J. Wen and M. H. Thiemens, J. Geophys. Res. 96, 10911 (1991).

${ }^{16}$ S. M. Anderson, K. Mauersberger, J. Morton, and B. Schueler, ACS Symposium Series, 1992 (unpublished).

${ }^{17}$ M. H. Thiemens, ACS Symposium Series, 1992 (unpublished).

${ }^{18}$ K. Mauersberger, J. Morton, B. Schueler, and J. Stehr, Geophys. Res. Lett. 20, 1031 (1993).

${ }^{19}$ D. Krankowsky, F. Bartecki, G. G. Klees, K. Mauersberger, and K. Schellenbach, Geophys. Res. Lett. 22, 1713 (1995).

${ }^{20}$ J. Schested, O. J. Nielsen, H. Egsgaard, N. W. Larsen, T. Pedersen, L. K. Christensen, and M. Wiegell, J. Geophys. Res. 100, 20979 (1995).

${ }^{21}$ M. H. Thiemens, Science 283, 341 (1999).

${ }^{22}$ D. Krankowsky and K. Mauersberger, Science 274, 1324 (1996).

${ }^{23}$ L. K. Christensen, N. W. Larsen, F. M. Nicolaisen, T. Pedersen, G. O. Sorensen, and H. Egsgaard, J. Mol. Spectrosc. 175, 220 (1996).

${ }^{24}$ J. C. Johnson and M. H. Thiemens, J. Geophys. Res. 102, 25395 (1997).

${ }^{25}$ S. M. Anderson, D. Husebusch, and K. Mauersberger, J. Chem. Phys. 107, 5385 (1997)

${ }^{26}$ K. Mauersberger, B. Erbacher, D. Krankowsky, J. Gunther, and R. Nickel, Science 283, 370 (1999).

${ }^{27}$ C. Janssen, J. Gunther, D. Krankowsky, and K. Mauersberger, J. Chem. Phys. 111, 7179 (1999).

${ }^{28}$ J. Guenther, B. Erbacher, D. Krankowsky, and K. Mauersberger, Chem. Phys. Lett. 306, 209 (1999).

${ }^{29}$ J. Gunther, D. Krankowsky, and K. Mauersberger, Chem. Phys. Lett. 324, 31 (2000).

${ }^{30}$ B. C. Hathorn and R. A. Marcus, J. Chem. Phys. 111, 4087 (1999).

${ }^{31}$ B. C. Hathorn and R. A. Marcus, J. Chem. Phys. 113, 9497 (2000).

${ }^{32}$ Y. Q. Gao and R. A. Marcus, Science 293, 259 (2001).

${ }^{33}$ Y. Q. Gao and R. A. Marcus, J. Chem. Phys. 116, 137 (2002).

${ }^{34}$ Y. Q. Gao, W. C. Chen, and R. A. Marcus, J. Chem. Phys. 117, 1536 (2002).

${ }^{35}$ R. Schinke, S. Y. Grebenshchikov, M. V. Ivanov, and P. Fleurat-Lessard, Annu. Rev. Phys. Chem. 57, 625 (2006).

${ }^{36}$ G. I. Gellene, Science 274, 1344 (1996).

${ }^{37}$ C. Janssen, J. Guenther, K. Mauersberger, and D. Krankowsky, Phys. Chem. Chem. Phys. 3, 4718 (2001).

${ }^{38}$ R. A. Marcus and Y. Q. Gao, J. Chem. Phys. 114, 9807 (2001).

${ }^{39}$ J. Troe, J. Chem. Phys. 66, 4745 (1977); 66, 4748 (1977); 77, 3485 (1982); 90, 4745 (1986)

${ }^{40}$ J. A. Miller, S. J. Klippenstein, and C. Raffy, J. Phys. Chem. A 106, 4904 (2002).

${ }^{41}$ Practical Handbook of Spectroscopy, edited by J. W. Robinson (CRC, Boca Raton, FL, 1991). 